\title{
Telemedicine for management of patients with amyotrophic lateral sclerosis through COVID-19 tail
}

\author{
Alessandro Bombaci ${ }^{1}$ - Gianmarco Abbadessa ${ }^{2,3}$ (D) - Francesca Trojsi ${ }^{4} \cdot$ Letizia Leocani ${ }^{5,6} \cdot$ Simona Bonavita $^{2}$. \\ Luigi Lavorgna $^{4}$ - on behalf of the Digital Technologies, Web and Social Media Study Group of the Italian Society of \\ Neurology
}

Received: 3 August 2020 / Accepted: 26 September 2020 / Published online: 6 October 2020

(C) The Author(s) 2020

\begin{abstract}
Over the last months, due to coronavirus disease (COVID-19) pandemic, containment measures have led to important social restriction. Healthcare systems have faced a complete rearrangement of resources and spaces, with the creation of wards devoted to COVID-19 patients. In this context, patients affected by chronic neurological diseases, such as amyotrophic lateral sclerosis (ALS), are at risk to be lost at follow-up, leading to a higher risk of morbidity and mortality. Telemedicine may allow meet the needs of these patients. In this commentary, we briefly discuss the digital tools to remotely monitor and manage ALS patients. Focusing on detecting disease progression and preventing life-threatening conditions, we propose a toolset able to improve ALS management during this unprecedented situation.
\end{abstract}

Keywords Telemedicine $\cdot$ Teleneurology $\cdot$ Tele-health $\cdot$ Remote monitoring $\cdot$ ALS patients $\cdot$ COVID-19

Coronavirus disease 2019 (COVID-19) has been spreading throughout the world, and, on 11th of March, the World Health Organization declared it to be pandemic [1]. Healthcare systems have suddenly faced an enormous and complete rearrangement of resources and spaces, with the

Alessandro Bombaci and Gianmarco Abbadessa contributed equally to this work.

Gianmarco Abbadessa

gianmarcoabbadessa@live.com

Luigi Lavorgna

Luigilavorgna@policliniconapoli.it

1 “Rita Levi Montalcini” Department of Neuroscience, University of Torino, Turin, Italy

2 Department of Advanced Medical and Surgical Sciences, II Clinic of Neurology, University of Campania “Luigi Vanvitelli”, Naples, Italy

3 Digital Technologies, Web and Social Media Study Group of the Italian Society of Neurology, Via Pansini 5, 80131 Naples, Italy

4 Department of Advanced Medical and Surgical Sciences, I Clinic of Neurology, University of Campania “Luigi Vanvitelli", Naples, Italy

5 Department of Neurorehabilitation, IRCCS San Raffaele Hospital, Milan, Italy

6 University Vita-Salute San Raffaele, Milan, Italy realization of wards entirely devoted to COVID-19 patients. Most of visits for chronic diseases have been canceled, postponed, or converted to teleconsultations (remote consultations between patients and clinicians) [2-4]. In the next months, this situation will probably persist. In this context, patients affected by chronic neurological diseases, such as amyotrophic lateral sclerosis (ALS), are at risk of being lost at follow-up with a consequently higher morbidity and mortality.

ALS is a neuromuscular progressive disorder, characterized by limb and bulbar muscle wasting and weakness. Thirty percent of patients present a bulbar onset, while $70 \%$ a spinal onset, although most of them develop bulbar impairment during the course of the disease [5]. Nowadays, there is still no curative treatment for ALS, and palliative care and symptomatic treatment are therefore essential components in the management of these patients. Death occurs in 3-5 years, generally due to respiratory paralysis [5-7]. Neurological examination and ALS Functional Rating Scale revised (ALSFRSr) are the most important tools to monitor disease progression. Early detection of severe symptoms, such as dysphagia and respiratory impairment, reduces the risk of developing $a b$ ingestis pneumonia and respiratory insufficiency, improving the prognosis [8]. Therefore, it is important to establish an efficient service of telemedicine to replace face-toface visits, monitor progression of the disease, and manage 
complications as soon as possible [2], especially lifethreatening ones. Herein, we briefly review the available instruments to remotely manage ALS patients with the aim of proposing a digital toolset (Fig.1) to face the current imposed stay-home policy.

ALSFRSr is commonly used to evaluate ALS progression. Some recent studies explored the possibility of an online selfadministered version of ALSFRSr scales $[9,10]$ reporting a high inter-rater and intra-rater reproducibility, and a low variability. Beyond ALSFRSr that can be easily compiled also by phone calls, performing a neurological examination remotely is also fundamental in the management of ALS. Recently, the American Academy of Neurology (AAN) published recommendations for improving a telemedicine service and suggested tools to perform a general neurological examination remotely [11]. Neurological examination through an audiovideo link showed good results in terms of reliability and validity with bedside examination $[12,13]$, although with some limitations in the assessment of muscle tone, vibration sensation, and deep tendon reflexes.

In order to overcome limits intrinsic to remote neurological examination, digital complementary tools have been proposed. Some sensors were developed to objectively homemonitoring ALS patients. Recent pivotal studies have investigated the feasibility of wearable devices equipped with an accelerometer for motor activity assessment and heart rate variability detection [14]. Remotely monitoring invasive and non-invasive ventilation through videoconferencing or homebased self-monitoring has strong application in telemedicine and in these patients could effectively reduce morbidity and mortality [15]. Even bulbar function could be monitored in

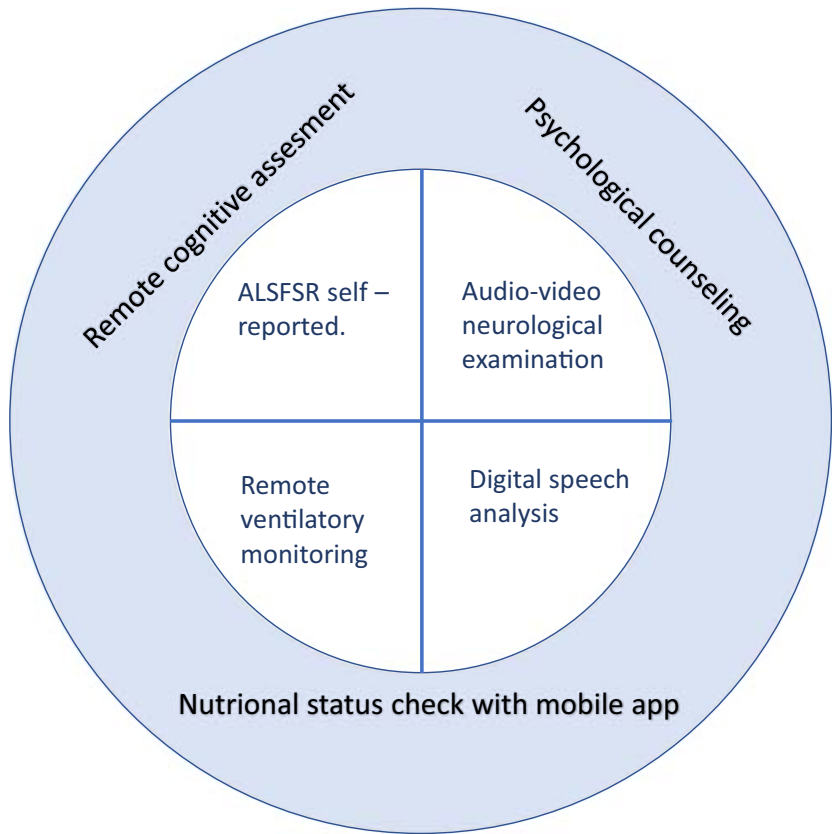

Fig. 1 Digital tool set for ALS management in remote during COVID-19 pandemic remote, through the analysis of the recordings of patients reading aloud a short paragraph, as Allison et al. reported [16]. They observed that the longitudinal evaluation of the percentage pause time expressed in seconds (a marker of speech fluency) is one of the most important markers of pre-clinical bulbar involvement in ALS. Another issue to be addressed is the monitoring of the nutritional status, which is a relevant prognostic factor. Countless nutrition-based mobile health (mHealth) applications are available for both Android and iOS. All are accessible and easy to use, but only few were assessed in clinical studies. In a recent randomized trial comparing remote nutritional counseling with or without mobile health technology in ALS patients, Nu Planit application was an acceptable and useful mobile app to check nutritional status [17]. It is a nutrition-based mHealth applications that facilitate frequent reminders and measurements. Patients can record their food habits and home weight measurements. Moreover, based on patients' gain or loss weight, the nutritionist could remotely access to the app and modify dietary recommendation. In ALS evaluation of cognitive profile is important because around $30-50 \%$ of patients develop cognitive impairment. A review highlighted the usefulness of some neuropsychological test administered by videoconference in new diagnosis and in follow-up [18]. Unfortunately, only few cognitive tests commonly used in ALS were tested, with a good agreement between videoconference and in clinic neuropsychological test. Receiving a diagnosis of a deadly illness such as ALS can deeply affect the emotional, physical, and mental aspects of a patients' life, and in these patients, also the psychological support is a key aspect of management. Transferring the meeting with the psychologist on a digital platform could be useful but not often accepted by the patients. Indeed, previous work on multidisciplinary digital management of ALS patients showed that psychological support was requested in few cases, probably due to personal refusal, embarrassment, or preference for a face-to-face contact [19].

All the issues debated point out the complexity of ALS patients' management and the need to create multidisciplinary teams able to face the new challenges due to this novel approach to patients' care [20]. As discussed in detail by Aghdam and colleagues, telemedicine offers a significant improvement in the organization of multidisciplinary team meetings compared with traditional settings. Indeed, it allows an improved access to and collaboration of medical experts. This results in an increased level of medical competence improving diagnosis, treatment, and patients' follow-up irrespective of location [21]. In an ongoing project, De Marchi and colleagues theorized that satisfactory multidisciplinary care could be provided to ALS patients in their home using technology. In this stay-home forced situation, they employed some of the tools discussed above in order to prevent a greater decline of the physical and psychological functions of ALS patients [22]. Despite the relevance of this approach is yet to be proven, they 
aimed to detect, as soon as possible, how it can be useful to avoid the postponed disease-related complications of this devastating disease, trying to support patients and their caregivers in the best way [22].

Overall, in our opinion, monitoring everyday life and potential life-threatening aspects of the disease should be the main goal of telemedicine in ALS patients, particularly at the time of COVID-19 pandemic [23, 24]. As mentioned, ALSFRSr and the neurological examination are the most important instruments to monitor disease status. Therefore, they should be part of the set core of remote examination (Fig. 1) and applied to all patients on follow-up teleconsultation. While the digital assessment of motor functions through digital devices, such as accelerometer, is not reliable in a context in which patients are forced to remain home, on the contrary, speech analysis for bulbar function and monitoring of invasive and non-invasive ventilation could be crucial in reducing morbidity and mortality and should be part of the set core. A study of remote pulmonary function tests was conducted by the Penn State Health Hershey ALS Center with patients, caregivers, and respiratory therapists reporting high acceptability [25]. Moreover, monitoring nutritional status through mHealth applications is useful and accessible, and we suggest the use of those apps for all ALS patients. A future perspective could be the development of an app in order to achieve a complete selfassessed evaluation of nutritional status, respiratory function, motor ability, and subjective perceived health status, as was already done for patients with Pompe disease [26].

The psychological support is very important especially immediately after diagnosis for both patients and their relatives. Remote psychological support could be essential in a period in which hospital access has been reduced. Therefore, patients and caregivers with psychological needs should receive the opportunity for scheduled psychotherapy or on-demand calls by a psychologist.

In a recent paper, Vasta and colleagues described their experience of telemedicine with the management of ALS patients during the COVID-19 pandemic. In agreement with previous studies, they revealed that patients reported to be globally satisfied with respect to the telemedicine service they received, but, despite the risk of contracting SARS-CoV2 infection, most of them would have preferred an impatient visit. Overall, the satisfaction of patients and caregivers for the use of telemedicine is good, although face-to-face visits are still largely preferred. Thus, telemedicine for ALS patients should have a complementary and not a substitutive role, and it should replace the in-person care depending on circumstances and patient preferences [27].

Limitations in the use of those complementary tools include the high costs to acquire the instrumentation to be given to patients, the training of patients' and caregivers, and the necessity of validation of some of these instrumentation and tools administered by videoconference or self-administered.
In conclusion, implementing telemedicine services for patients with ALS is necessary to allow direct clinical evaluation during COVID-19 pandemic, in order to plan the appropriate medical and nursing care, avoiding hospitalizations or urgent interventions.

Acknowledgements Open access funding provided by Università degli Studi della Campania Luigi Vanvitelli within the CRUI-CARE Agreement. Digital Technologies, Web and Social Media Study Group of Italian Neurological Society (SIN)

Gioacchino Tedeschi, Department of Advanced Medical and Surgical Sciences, University of Campania "Luigi Vanvitelli", Naples; Giovanni Mancardi, Department of Neuroscience, Rehabilitation, Ophthalmology, Genetics, Maternal and Child Health, University of Genova; Alessandro Padovani, Neurology Unit, Department of Clinical and Experimental Sciences, University of Brescia; Marinella Clerico, Clinical and Biological Sciences Department, Neurology Unit, University of Torino; Francesco Brigo, Department of Neurology, Franz Tappeiner Hospital, Merano; Eleonora Cocco, Department of Medical Sciences and Public Health, University of Cagliari; Roberta Lanzillo, Department of Neuroscience, Reproductive Science and Odontostomatology, Federico II University of Naples; Antonio Russo, Department of Advanced Medical and Surgical Sciences, University of Campania "Luigi Vanvitelli", Naples; Bruno Giometto, Department of Neurology, Ospedale Santa Chiara, Trento; Giulia Straccia, Department of Advanced Medical and Surgical Sciences, University of Campania "Luigi Vanvitelli", Naples; Rosa Iodice, Department of Neuroscience, Reproductive Science and Odontostomatology, Federico II University of Naples; Sebastiano Bucello, Department of Neurology, Azienda Ospedaliera Asp 8 Siracusa, C.da Granatello, Augusta; Pietro Annovazzi, Department of Neurology, Gallarate Hospital, Milano; Marcello Moccia, Department of Neuroscience, Reproductive Science and Odontostomatology, Federico II University of Naples; Luca Prosperini, Department of Neurosciences, Ospedale San Camillo Forlanini, Rome; Maria Laura Stromillo, Department of Medicine, Surgery and Neuroscience, University of Siena; Anna Maria Repice, Department of Neurology, AOU Careggi, Firenze; Giuseppina Miele, Department of Advanced Medical and Surgical Sciences, II Clinic of Neurology, University of Campania "Luigi Vanvitelli," Naples; Alberto Lerario, Policlinico Hospital of Milan; Antonio De Martino, Institute of Neurology, University of Catanzaro; Francesco Iodice, Institute of Neurology, Catholic University of Sacred Heart, Rome; Francesco Di Lorenzo, Non Invasive Brain Stimulation Unit, IRCSS Fondazione Santa Lucia, Rome; Luca Cuffaro, Department of Biomedicine, Neuroscience and Advanced Diagnostic, University Hospital "Paolo Giaccone", Palermo; Michele Romoli, Neurology Clinic, University of Perugia, Perugia; Marcello Silvestro, Department of Advanced Medical and Surgical Sciences, University of Campania "Luigi Vanvitelli", Naples; Carlo Alberto Artusi, Department of Neuroscience "Rita Levi Montalcini”, University of Torino.

Authors' contribution Alessandro Bombaci and Gianmarco Abbadessa equally contributed to the conception of the study, literature revision, and manuscript drafting; Francesca Trojsi and Letizia Leocani contributed to the conception of the study and revised the article and table for intellectual content; Luigi Lavorgna and Simona Bonavita contributed to the conception of the study and final revision of the article and table. All authors equally contributed to the final approval of the version to be submitted.

\section{Compliance with ethical standards}

Conflict of interest None. 


\section{Ethical approval None.}

Open Access This article is licensed under a Creative Commons Attribution 4.0 International License, which permits use, sharing, adaptation, distribution and reproduction in any medium or format, as long as you give appropriate credit to the original author(s) and the source, provide a link to the Creative Commons licence, and indicate if changes were made. The images or other third party material in this article are included in the article's Creative Commons licence, unless indicated otherwise in a credit line to the material. If material is not included in the article's Creative Commons licence and your intended use is not permitted by statutory regulation or exceeds the permitted use, you will need to obtain permission directly from the copyright holder. To view a copy of this licence, visit http://creativecommons.org/licenses/by/4.0/.

\section{References}

1. WHO Director-General's opening remarks at the media briefing on COVID-19 - 11 March 2020. https://www.who.int/dg/speeches/ detail/who-director-general-s-opening-remarks-at-the-mediabriefing-on-covid-19\%2D\%2D-11-march-2020.

2. Technology enabled care services. Resource for Commissioners. January 2015. NHS Commissioning Assembly. https://www. england.nhs.uk/wp-content/uploads/2014/12/TECS_FinalDraft_ 0901.pdf

3. Waldman G, Mayeux R, Claassen J, Agarwal S, Willey J, Anderson E, Punzalan P, Lichtcsien R, Bell M, Przedborski S, Ulane C, Roberts K, Williams O, Lassman AB, Lennihan L, Thakur KT (April 2020) Preparing a neurology department for SARS-CoV-2 (COVID-19): early experiences at Columbia University Irving Medical Center and the New York Presbyterian Hospital in New York City. Neurology. 94:886-891. https://doi. org/10.1212/WNL.0000000000009519

4. Bonavita S, Tedeschi G, Atreja A, Lavorgna L (2020) Digital triage for people with multiple sclerosis in the age of COVID-19 pandemic. Neurol Sci 41(5):1007-1009. https://doi.org/10.1007/s10072020-04391-9

5. Hardiman O, Al-Chalabi A, Chio A et al (2017) Amyotrophic lateral sclerosis. Nat Rev Dis Prim 3(1):17071. https://doi.org/10. 1038/nrdp.2017.71

6. Lombardi V, Bombaci A, Zampedri L, et al. (2020) Plasma pNfH levels differentiate SBMA from ALS. Journal of Neurology, Neurosurgery and Psychiatry. 91(2). https://doi.org/10.1136/jnnp2019-320624

7. Brown RH, Al-Chalabi A (2017 Jul 13) Amyotrophic lateral sclerosis. N Engl J Med 377(2):162-172. https://doi.org/10.1056/ NEJMra1603471

8. Miller RG, Jackson CE, Kasarskis EJ, England JD, Forshew D, Johnston W, Kalra S, Katz JS, Mitsumoto H, Rosenfeld J, Shoesmith C, Strong MJ, Woolley SC, Quality Standards Subcommittee of the American Academy of Neurology (2009) Practice parameter update: the care of the patient with amyotrophic lateral sclerosis: drug, nutritional, and respiratory therapies (an evidence-based review): report of the quality standards subcommittee of the American Academy of Neurology. Neurology. 73(15):1218-1226. https://doi.org/10.1212/WNL. 0b013e3181bc0141

9. Bakker L, Schröder C, Tan H et al (2020) Development and assessment of the inter-rater and intra-rater reproducibility of a selfadministration version of the ALSFRS-R. J Neurol Neurosurg Psychiatry 91:75-81. https://doi.org/10.1136/jnnp-2019-321138

10. Berry JD, Paganoni S, Carlson K, Burke K, Weber H, Staples P, Salinas J, Chan J, Green JR, Connaghan K, Barback J, Onnela JP
(2019) Design and results of a smartphone-based digital phenotyping study to quantify ALS progression. Ann Clin Transl Neurol 6(5):873-881. https://doi.org/10.1002/acn3.770

11. American Academy of Neurology. Telemedicine and remote care. AAN COVID-19 Neurol Resour. https://www.aan.com/tools-andresources/practicing-neurologists-administrators/telemedicine-andremote-care/. Accessed April 25, 2020

12. Pulley MT, Brittain R, Hodges W, Frazier C, Miller L, MatyjasikLiggett M, Maurer S, Peters M, Solomon K, Berger AR (2019) Multidisciplinary amyotrophic lateral sclerosis telemedicine care: the store and forward method. Muscle Nerve 59(1):34-39. https:// doi.org/10.1002/mus.26170

13. Awadallah M, Janssen F, Körber B, Breuer L, Scibor M, Handschu R (2018) Telemedicine in general neurology: interrater reliability of clinical neurological examination via audio-visual telemedicine. Eur Neurol 80(5-6):289-294. https://doi.org/10.1159/000497157

14. Garcia-Gancedo L, Kelly ML, Lavrov A, et al. (2019) Objectively monitoring amyotrophic lateral sclerosis patient symptoms during clinical trials with sensors: observational study. J Med Internet Res. 21(12). https://doi.org/10.2196/13433

15. Pinto A, Almeida JP, Pinto S, Pereira J, Oliveira AG, De Carvalho M (2010) Home telemonitoring of non-invasive ventilation decreases healthcare utilisation in a prospective controlled trial of patients with amyotrophic lateral sclerosis. J Neurol Neurosurg Psychiatry 81(11):1238-1242. https://doi.org/10.1136/jnnp.2010. 206680

16. Allison KM, Yunusova Y, Campbell TF, Wang J, Berry JD, Green JR. (2018) The diagnostic utility of patient-report and speechlanguage pathologists' ratings for detecting the early onset of bulbar symptoms due to ALS HHS Public Access. https://doi.org/10.1080/ 21678421.2017.1303515

17. Wills AM, Garry J, Hubbard J, Mezoian T, Breen CT, Ortiz-Miller C, Nalipinski P, Sullivan S, Berry JD, Cudkowicz M, Paganoni S, Chan J, Macklin EA (2019) Nutritional counseling with or without mobile health technology: a randomized open-label standard-ofcare-controlled trial in ALS. BMC Neurol 19(1):104. https://doi. org/10.1186/s12883-019-1330-6

18. Brearly TW, Shura RD, Martindale SL, Lazowski RA, Luxton DD, Shenal BV, Rowland JA (2017) Neuropsychological test administration by videoconference: a systematic review and meta-analysis. Neuropsychol Rev 27(2):174-186. https://doi.org/10.1007/s11065017-9349-1

19. Vitacca M, Comini L, Tentorio M, Assoni G, Trainini D, Fiorenza D, Morini R, Bruletti G, Scalvini S (2010) A pilot trial of telemedicine-assisted, integrated care for patients with advanced amyotrophic lateral sclerosis and their caregivers. J Telemed Telecare 16(2): 83-88. https://doi.org/10.1258/jtt.2009.090604

20. Pinto S, Quintarelli S, Silani V (2020) New technologies and amyotrophic lateral sclerosis - which step forward rushed by the COVID19 pandemic? J Neurol Sci 418:117081. https://doi.org/10.1016/j. jns.2020.117081

21. Aghdam MRF, Vodovnik A, Hameed RA (2019) Role of telemedicine in multidisciplinary team meetings. J Pathol Inform;10:35. Published 2019 Nov 18. https://doi.org/10.4103/jpi.jpi_20_19

22. De Marchi F, Cantello R, Ambrosini S, Mazzini L, CANPALS Study Group (2020) Telemedicine and technological devices for amyotrophic lateral sclerosis in the era of COVID-19. Neurol Sci 41(6):1365-1367. https://doi.org/10.1007/s10072-020-04457-8

23. Hobson EV, Baird WO, Partridge R, Cooper CL, Mawson S, Quinn A, Shaw PJ, Walsh T, Wolstenholme D, Mcdermott CJ (2018) The TiM system: developing a novel telehealth service to improve access to specialist care in motor neurone disease using user-centered design. Amyotroph Lateral Scler Frontotemporal Degener. 19(5-6):351-361. https://doi.org/10. $1080 / 21678421.2018 .1440408$ 
24. Hobson EV, Baird WO, Bradburn M et al. (2019) Using telehealth in motor neuron disease to increase access to specialist multidisciplinary care: a UK-based pilot and feasibility study. BMJ Open;9(10):e028525. Published 2019 Oct 22. https://doi.org/10. 1136/bmjopen-2018-028525

25. Geronimo A, Simmons Z (2019) Evaluation of remote pulmonary function testing in motor neuron disease. Amyotroph Lateral Scler Frontotemporal Degener 20(5-6):348-355. https://doi.org/10. 1080/21678421.2019.1587633

26. Ricci G, Baldanzi S, Seidita F, Proietti C, Carlini F, Peviani S, Antonini G, Vianello A, Siciliano G, Musumeci O, Toscano A, Ravaglia S, Moggio M, Comi G, Pegoraro E, Filosto M, Marrosu G, Maggi L, Liguori R, Massa R, di Iorio G, Servidei S, Angelini C, Mongini T (2018) A mobile app for patients with Pompe disease and its possible clinical applications. Neuromuscul Disord 28(6): 471-475. https://doi.org/10.1016/j.nmd.2018.03.005

27. Vasta R, Moglia C, D’Ovidio F, di Pede F, de Mattei F, Cabras S, Peotta L, Iazzolino B, Giusiano S, Manera U, Palumbo F, Bombaci A, Torrieri MC, Ilardi A, Mastro E, Arcari M, Solero L, Grassano M, Daviddi M, Matteoni E, Salamone P, Fuda G, Canosa A, Chiò A, Calvo A (2020) Telemedicine for patients with amyotrophic lateral sclerosis during COVID-19 pandemic: an Italian ALS referral center experience. Amyotrophic Lateral Sclerosis and Frontotemporal Degeneration:1-4. https://doi.org/10.1080/ 21678421.2020.1820043

Publisher's note Springer Nature remains neutral with regard to jurisdictional claims in published maps and institutional affiliations. 